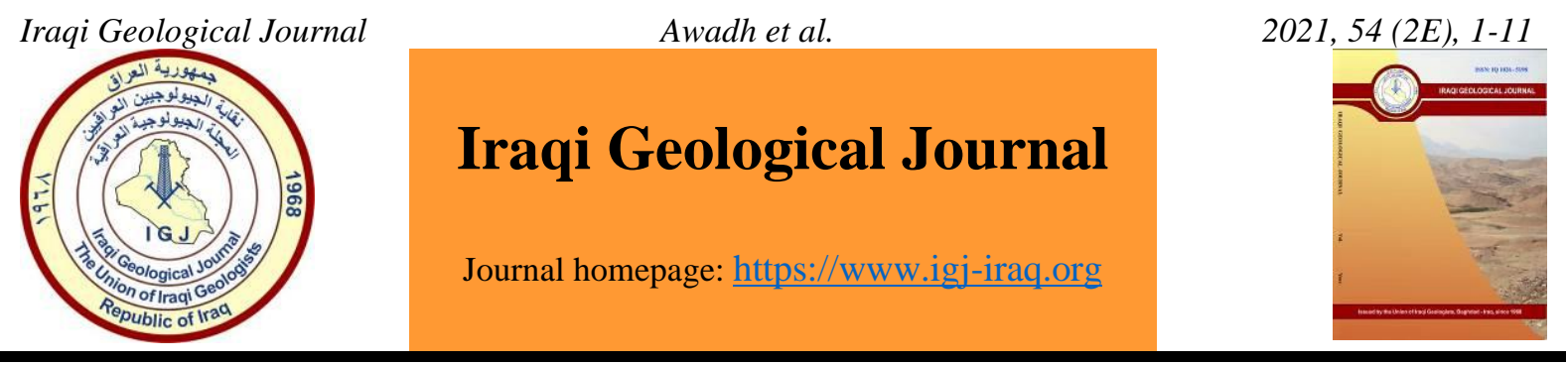

\title{
Ore Petrography, Mineralogical and Chemical Composition of New Iron Meteorite (Al-Sherqat Meteorite) from Iraq
}

\author{
Salih Muhammad Awadh ${ }^{1, *}$, Salih Y. Darweesh ${ }^{2}$ and Salman Z. Khorshid ${ }^{2}$ \\ 1 Department of Geology, College of Science, University of Baghdad, Baghdad, Iraq \\ 2 Department of Physics, College of Education, Tuzkhurmato, Tikrit University, Iraq \\ * Corresponding author: salih.awadh@sc.uobaghdad.edu.iq
}

Received: 5 September 2021; Accepted: 3 October 2021; Published: 30 November 2021

\begin{abstract}
The meteorite with a single total mass of $630 \mathrm{gm}$ as a visible meteorite has fallen on 22 March 2021, at 10:00 a.m. in Al-Sherqat subdistrict within Salah Al-Din governorate in northern Iraq; and therefore, was named AlSherqat meteorite by the authors. It is characterized by a uniform structure of coherent and medium degree of malleability. It is of a well-crystalline structure and not homogeneous in composition. The Al-Sherqat meteorite is composed of metallic phases of $7.6 \mathrm{gm} / \mathrm{cm}^{3}$ density exhibiting an oriented intergrowth of kamacite $(\alpha-\mathrm{FeNi})$ with taenite showing a Widmanstätten pattern on an etched polished section with the finest octahedrite kamacite bandwidth of less than $0.2 \mathrm{~mm}$. It is composed of Fe (86.9 wt $\%)$, Ni (9.63 wt \%), P (1.31 wt \%), S (0.628 wt \%), Ti $(0.623 \mathrm{wt} \%)$, Co (0.446 wt \%), Mo (0.146 wt \%), Cr (0.103 wt \%), Cu (0.141 wt \%), V(300 ppm), Nb (220 ppm), W(53 ppm), Ag (50 ppm), Pb (30 ppm), Zn (20 ppm), Sb (16 ppm), Sn (10 ppm) and As (3 ppm). AlSherqat meteorite was structurally classified as an iron meteorite belongs to plessitic group (Opl)) with octahedrite finest bands (less than $0.2 \mathrm{~mm}$ ) of the kamacite lamellae. Kamacite platelets in Al-Sherqat meteorite are almost not a continuous plate network. Chemically, it belongs to the IIC type of magmatic group based on the amount of nickel $(9.63 \%)$, where IIC is typically octahedrites has $9.3-11.5 \% \mathrm{Ni}$. The presence of kamacite, taenite, schreibersite, daubréelites, pentlandite, chromite, and wusite in Al-Sherqat meteorite are in accordance with IIC group of the iron meteorites. Al-Sherqat meteorite belongs to M-type considering a metallic core fragmented by impact asteroid. The most probable source of this meteorite is the core of an asteroid that melted early in its history.
\end{abstract}

Keywords: Iron meteorite; kamacite; Taenite; Widmanstätten pattern; IIC

\section{Introduction}

Over the past centuries, and so far, only three main types of meteorites have been known: stony meteorites, iron-stony meteorites, and iron meteorites. The stony meteorites are composed mainly of silicates and called aerolites; the stony-iron meteorites are called siderolites composing of both metallic and silicates, forming from pallasites or mesosderites; and the iron meteorites, named also siderites (Weisberg et al., 2006) are composed entirely of metals either nickel-poor kamacite or nickelrich taenite, which often occurs together (Howe and Knott,1962). The crystals of these two minerals are often interlocked and combined to form a characteristic feature named the Widmanstätten pattern which indicates the relatively low pressure at which iron meteorites are formed. The Widmanstatten pattern develops at low temperatures during the evolution of the asteroids (Yang and Goldstein,

DOI: $\underline{10.46717 / i g j .54 .2 E .1 M s-2021-11-17 ~}$ 
2004). Hexahedrites, octahedrites, and ataxites can be revealed in the iron meteorite by etching a polished section by dilute acid. Hexahedrites are entirely formed from kamacite and lack the Widmanstätten pattern, whereas, the octahedrite is composed of both kamacite and taenite (Wasson, 1969). The ataxites are made up of pure taenite as some of them consist of $69 \%$ Ni (Novotny et al., 1982). The most common of the iron meteorites are octahedrite, and the rarest are ataxites (amorphous irons) (Farrington,1901). It is very necessary to investigate the kamacite and taenite arrays to classified the iron meteorites. The chemistry of such alloys can provide useful information of great significance about how the metallic cores of planets formed. Kamacite is a pole of shaft broadly banded alloy, taenite is a ribbon characterized by a narrow alloy banded., whereas, plessite represents an alloy intermediate in properties between kamacite and taenite which fills in the angular interstices that occur between the intersecting bands. For this, Reichenbach gave the name of Fulleisen or plessite (Granvik and Brown, 2018). The research aims mainly to document the fall of a new meteorite in the area of Al-Sherqat in northern Iraq, and also to introduce a detailed description of the meteorite's mineralogy, chemistry, and classification as well as the probable origin.

\section{Sample and Analytical Methods}

Since we only have a small piece of the meteorite, the sample was handled very carefully to ensure completing all the required analyzes and tests. A small portion of the meteorite sample was crushed by an agate mortar to prevent contamination of the sample, and used for the X-ray diffraction (XRD) and $\mathrm{X}$-Ray fluorescence (XRF) for the mineralogical and chemical analyses respectively which have been conducted at the lab of Environmental, Water Research, and Technology Directorate, Ministry of Science and Technology in Iraq. A polished section sample was made (Fig. 1) in the workshop of the Department of Geology, College of Science, the University of Baghdad using the standard procedure stated by Craig et al., (1981). Ore mineralogy and textures were described using a reflected light microscope, type Lietz, Germany made. One polished section was etched by concentrated $\mathrm{HNO}_{3}$ to increase the texture clarity and describe the Widmanstätten patterns.

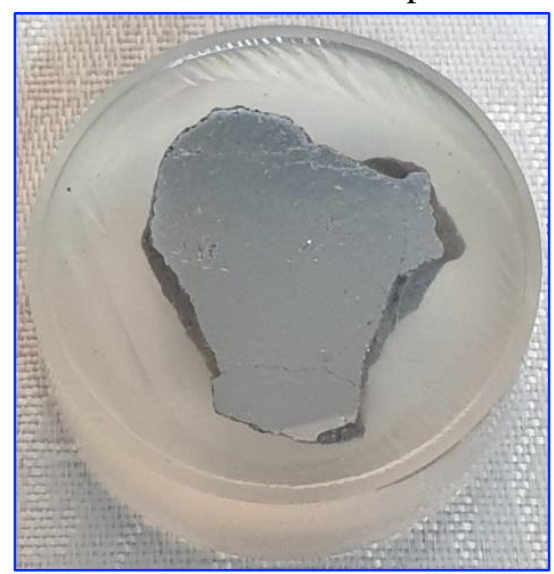

Fig.1. Polished section of Al-Sherqat Meteorite

\section{Results and Discussion}

\subsection{The Witness Story and Description}

The meteorite has fallen on 22 March 2021, at 10:00 p.m. in an area called Al-Qasbah, which is one of the villages of Al-Sherqat sub-district in Salah al-Din governorate, north of Baghdad. One of the witnesses claimed to have seen the meteorite as it fell in their village at night with a total weight of 630 gm. The exact location was determined by the coordinates of $35^{\circ} 31^{\prime} 22.95^{\prime \prime}$ and $43^{\circ} 13^{\prime} 52.48^{\prime \prime}$. The 
meteorite has fallen with an incidence angle of about $70^{\circ}$ as a brilliant ball of fire with a smoky whitetail moving from the northwest (N20W) to the southeast at tremendous speed. The meteorite impact left a crater estimated at $0.5 \mathrm{~m}$ deep with an oval diameter ranging $0.5 \times 1.5 \mathrm{~m}$. Unfortunately, the witness doesn't provide photos of the crater. Then the meteorite has been rolled in form of a red cinder and eventually settled out of its crater. After it got cold, immediately was collected by the narrator who has provided us with a small piece of it. Al-Sherqat meteorite shows remarkable uniformity of its structure with strongly coherent and tenacious to a high degree of malleability with a very clear of a dark fusion crust (1mm thick approximately) which is formed on a surface of meteorite during its passage through the atmosphere (Fig.2). It has a cryptocrystalline to the crystalline texture of gray color with a metallic luster. It has a $7.6 \mathrm{gm} / \mathrm{cm}^{3}$ density and attracts magnets (Fig.2c).

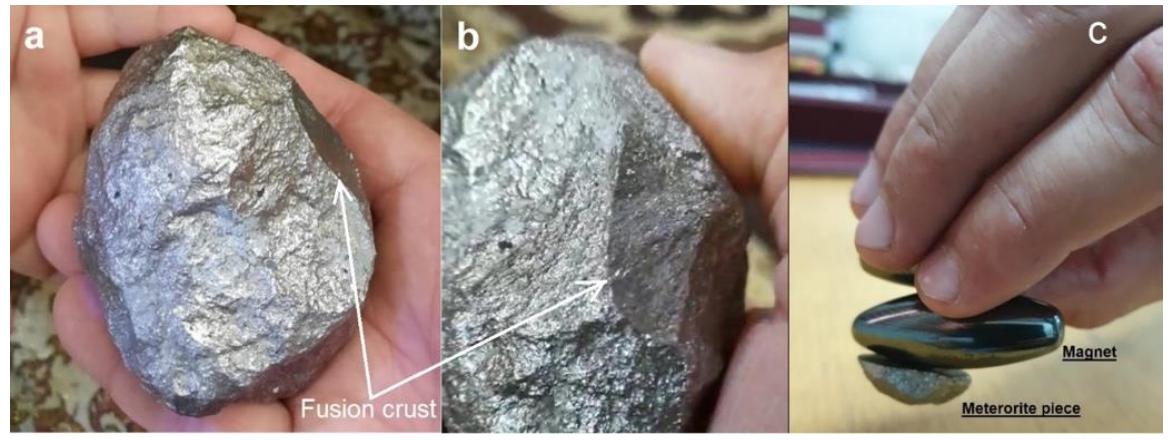

Fig.2. The total mass of Al-Sherqat meteorite showing dark fusion crust (a\&b) and attracts magnet (c)

\subsection{Mineralogy and Ore Petrography}

The Al-Sherqat meteorite has a structure of remarkable uniformity. The mineralogical composition of the meteorite was investigated using XRD as well as the reflected light microscope. The meteorite is composed of kamcite, taenite, schreibersite, daubreelite; chromite, pentlandite and wusite (Fig. 3). The meteorite began to melt upon collides the atmosphere; then, iron has interacted with oxygen forming magnetite in the form of a fusion crust not exceeding $1 \mathrm{~mm}$ thick enveloping the meteorite (Fig. $2 \mathrm{a} \mathrm{\& b}$ ), accordingly iron can react with oxygen under high temperature forming wusite. Unfortunately, the piece given to us by the person who collected the meteorite did not contain molten crust, so it was not analyzed. Kamacite is a predominant mineral in the meteorite as a metal alloy composed of iron and nickel. Taenite is scattered in the form of irregularly shaped and unconnected nickel-rich grains spreading in a groundmass of kamacite (Plate $1 \mathrm{a}-\mathrm{f}$ ), where both kamacite and taenite are showing isotropic properties. The scratches of the polishing hardness of meteorite indicate soft to medium polishing hardness. Fine grains of schreibersite occur in the form of irregular masses scattering in the groundmass of the kamacite (Plate $1 \mathrm{~g}$-i). It was possible to see many microscopic and macro fractures which are believed to have been formed due to the impact of the meteorite on the Earth's surface (Plate $2 \mathrm{a} \& \mathrm{~b}$ ). They are considered shock-induced deformations. Melt pockets and other microstructural features are also common in iron meteorites (Olsen et al., 1994). The acid-treated polished section shows distinct Widmanstätten patterns reflecting bands made up of different nickel contents (Plate $2 \mathrm{a} \& b$ ). The Neumann lines; fine sets of parallel lines that can be formed in kamacite due to the development of twinning (Khalaf et al., 2015) do not occur. Widmanstatten patterns represent series of parallel bands meaning a well crystalline heterogeneous composition (Yang et al., 2011). Octahedral arrays of Widmanstätten patterns were identified after etching by $\mathrm{HNO}_{3}$ (Plate 2c). The mineralogical composition (\%) of Al-Sherqat meteorite was roughly calculated based on the chemistry and microscopic data of meteorite and listed in Table 1. 


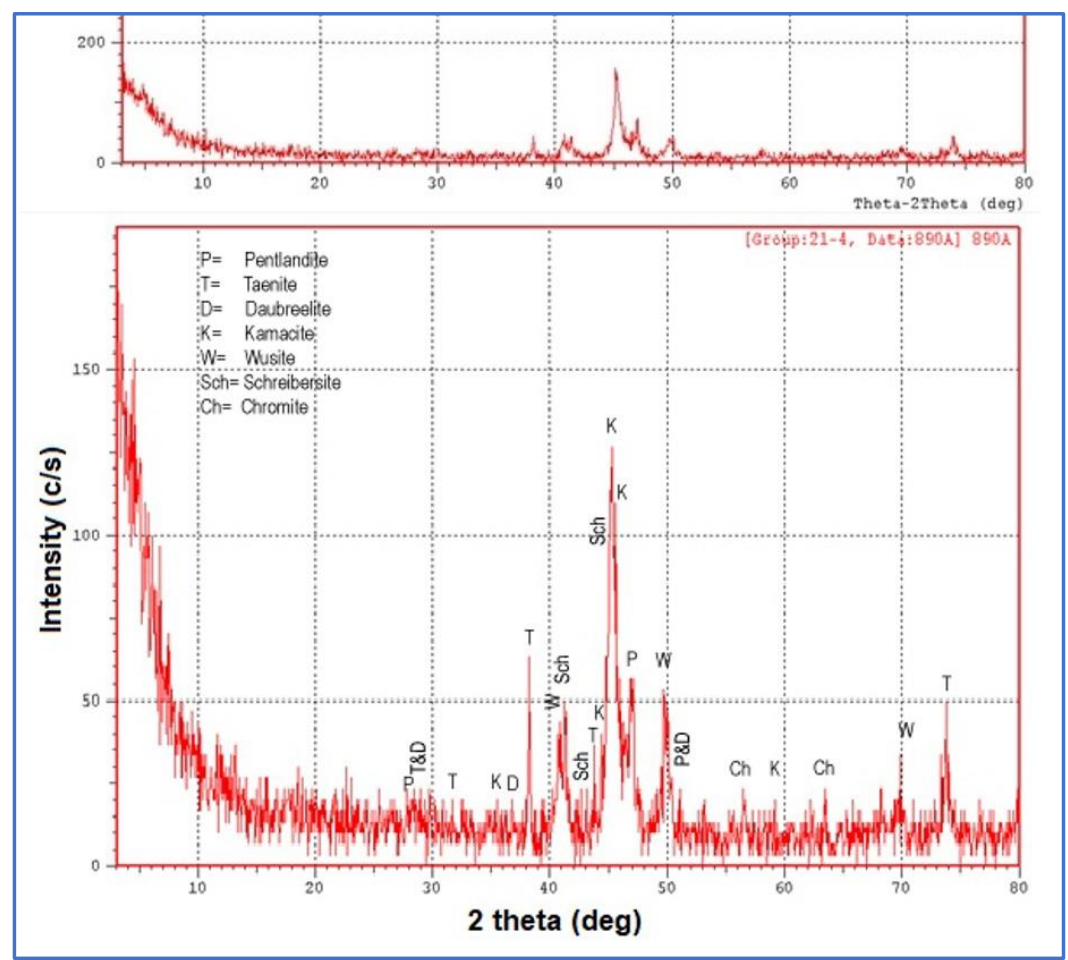

Fig. 3. XRD diffractogram showing the mineralogical composition of the meteorite

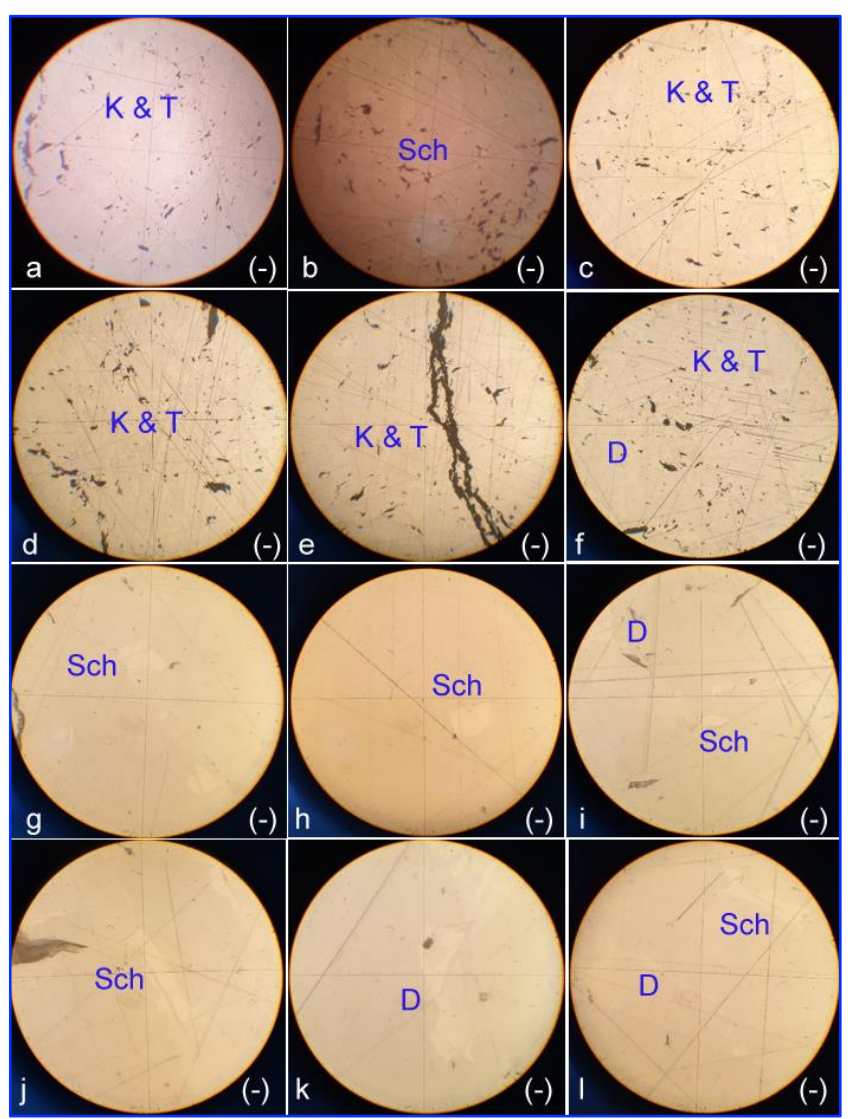

Plate 1. Photomicrograph of Al-Sherqat meteorite using reflected light microscope; K) kamacite; T) taenite; Sch) schersbersite; D) daubréelite. The variation in color is due to kamacite and taenite distribution reflecting the nickel content. All photos were taken using lens 5X. a-f; Kamacite-taenite alloy of different composition of Ni content illustrating soft to medium polishing hardness. Images were taken by lens $5 \mathrm{X}$ 


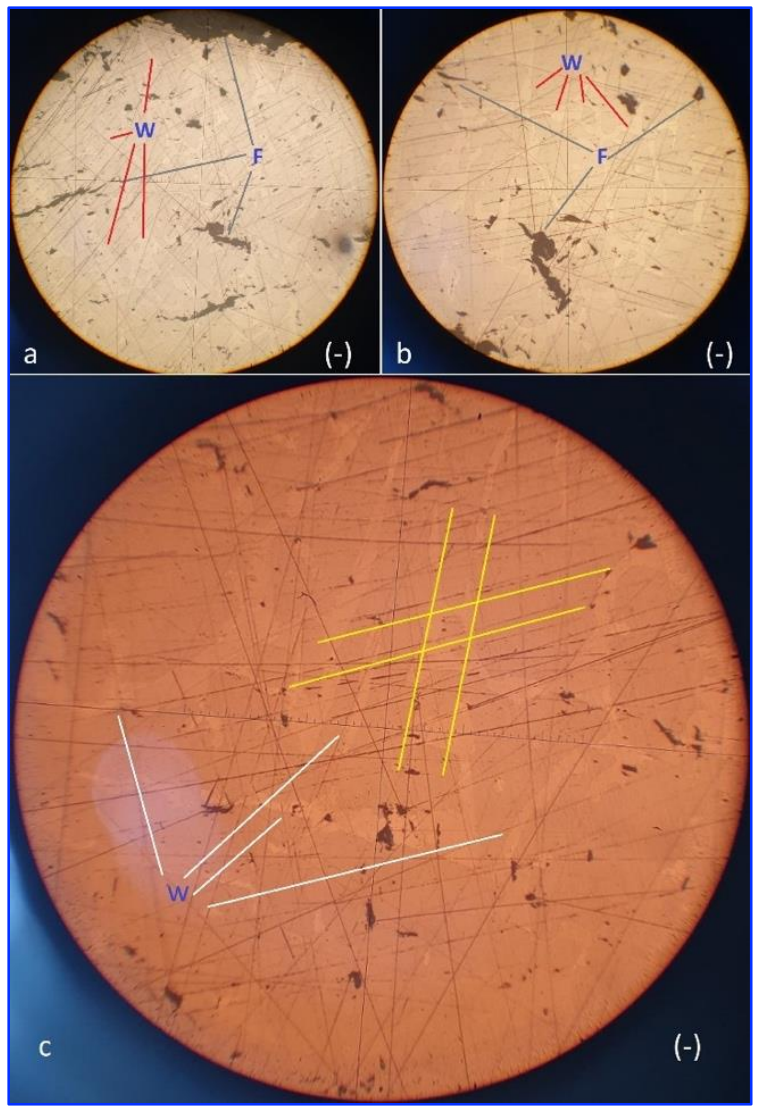

Plate 2. Photomicrographs of polished section showing octahedral array of Widmanstätten patterns (W) in the meteorite after etching by $\mathrm{HNO}_{3}$. The texture of meteorite has a lot of fractures (F); Images were taken by lens $5 \mathrm{X}$.

Table. 1. Mineralogical composition (\%) of Al-Sherqat meteorite

\begin{tabular}{lcc}
\hline Minerals & Chemical composition & \% \\
\hline Kamacite & $\alpha-\mathrm{Fe}, \mathrm{Ni}$ & 74.0 \\
Taenite & $\gamma-\mathrm{Fe}, \mathrm{Ni}$ & 14.0 \\
Schreibersite & $(\mathrm{Fe}, \mathrm{Ni})_{3} \mathrm{P}$ & 8.48 \\
Pentlandite & $(\mathrm{Ni}, \mathrm{Fe})_{9} \mathrm{~S}_{8}$ & 0.60 \\
Daubréelite & $\mathrm{FeCr}_{2} \mathrm{~S}_{4}$ & 1.81 \\
Chromite & $\mathrm{FeCr}_{2} \mathrm{O}_{4}$ & 0.60 \\
Wusite & $\mathrm{FeO}$ & 0.51 \\
Total & & 100 \\
\hline
\end{tabular}

\subsection{Meteorite Chemical Composition}

The formula of kamacite $\left(\mathrm{Fe}_{14} \mathrm{Ni}\right)$ generally expresses the usual proportion of $\mathrm{Fe}: \mathrm{Ni}$; whereas, it has been of high nickel $\left(\mathrm{Fe}_{6} \mathrm{Ni}\right.$ and $\left.\mathrm{Fe}_{5} \mathrm{Ni}_{2}\right)$ for taenite. For this reason, kamacite is much more soluble in acid than taenite; and alloys $\left(\mathrm{Fe}_{14} \mathrm{Ni}, \mathrm{Fe}_{6} \mathrm{Ni}\right.$, and $\left.\mathrm{Fe}_{5} \mathrm{Ni}_{2}\right)$ are typically named triad (Dell'Aglio et al., 2010). The kamacite is basically consisted of iron-nickel alloy (Fe $89.54 \%$ and $\mathrm{Ni} 10.46 \%$ ) with the chemical formula $\mathrm{Fe}_{0.9} \mathrm{Ni}_{0.1}$ (Litasov et al., 2019). The chemical composition (major and trace elements) of Al-Sherqat meteorite is listed in Table 2. It is formed mainly of Fe (86.9\%) and nickel (9.63\%) with a significant amount of $\mathrm{P}(1.31 \%)$. The phosphorus is involved to form schreibersite $(\mathrm{Fe}, \mathrm{Ni})_{3} \mathrm{P}$ forming $8.48 \%$ from the meteorite as it has the chemical composition (Fe 62.36\%, Ni $21.94 \%$ and $\mathrm{P} 15.44 \%$ ). 
The main amount of iron is involved to form kamacite and taenite. An alloy of iron and nickel has almost formed kamacite $(75 \%)$ and taenite $(14 \%)$ with chemical formulas as $\mathrm{Fe}_{0.94} \mathrm{Ni}_{0.6}$ and $\mathrm{Fe}_{0.95} \mathrm{Ni}_{0.5}$ respectively. Cobalt, C, P, and S are common elements in kamacite. Sulfur is involved in pentlandite $(\mathrm{Ni}, \mathrm{Fe})_{9} \mathrm{~S}_{8}$ and daubréelite $\left(\mathrm{FeCr}_{2} \mathrm{~S}_{4}\right)$, while chromium is involved to form chromite $\left(\mathrm{FeCr}_{2} \mathrm{O}_{4}\right)$ and daubréelite as well. A very small percentage of wusite was formed due to the oxidation of the outer surface of the meteorite at high temperatures during the combustion of the meteorite after impacting with the atmosphere.

Table 2. Chemical composition of Al-Sherqat meteorite

\begin{tabular}{lll}
\hline Elements & \multicolumn{2}{l}{ Chemical composition } \\
\hline & $(\boldsymbol{\%})$ & ppm \\
$\mathrm{Fe}$ & 86.9 & --- \\
$\mathrm{Ni}$ & 9.63 & --- \\
$\mathrm{P}$ & 1.31 & --- \\
$\mathrm{S}$ & 0.628 & 6280 \\
$\mathrm{Ti}$ & 0.623 & 6230 \\
$\mathrm{Co}$ & 0.446 & 4460 \\
$\mathrm{Mo}$ & 0.146 & 1460 \\
$\mathrm{Cu}$ & 0.141 & 1410 \\
$\mathrm{Cr}$ & 0.103 & 1030 \\
$\mathrm{Nb}$ & 0.022 & 220 \\
$\mathrm{~W}$ & 0.0053 & 53 \\
$\mathrm{Ag}$ & 0.005 & 50 \\
$\mathrm{~Pb}$ & 0.003 & 30 \\
$\mathrm{~V}$ & 0.003 & 30 \\
$\mathrm{Zn}$ & 0.002 & 20 \\
$\mathrm{Sb}$ & 0.0016 & 16 \\
$\mathrm{Sn}$ & 0.001 & 10 \\
$\mathrm{As}$ & 0.0003 & 3 \\
$\mathrm{Total}$ & 99.97 & \\
\hline
\end{tabular}

\subsection{Meteorite Classification}

The iron meteorites are mostly classified based on the width of the octahedral array of kamacite ( $\alpha$ $\mathrm{Fe}, \mathrm{Ni})$. Nearly all the remainder are either hexahedrites composed almost entirely of kamacite, which shows a cubic cleavage, or ataxites composed largely of taenite $(\gamma-\mathrm{Fe}, \mathrm{Ni})$. The systematic differences in the mineralogy, chemistry, and structure resulted in $86 \%$ from the iron meteorite are assigned to one of 12 genetic groups, whereas the rest $14 \%$ are anomalous (Scott and Wasson, 1975). Bulk density is a useful parameter to identify meteorites from terrestrial rocks as meteorites have bulk densities higher than common terrestrial rocks. The bulk density of Al-Sherqat meteorite $\left(7.6 \mathrm{gm} / \mathrm{cm}^{3}\right)$ compared with many types of terrestrial rocks and meteorites confirmed an iron meteorite (Fig.4). Structurally, AlSherqat meteorite is classified as an octahedral plessitic group (Opl) which means that meteorite has finest kamacite platelets with less than $0.2 \mathrm{~mm}$ do not form continuous network (Table 3\&4). Chemically, it was classified as IIC of magmatic group, which is an octahedrite that has $9.3-11.5 \% \mathrm{Ni}$ (Table 4). The iron meteorites are ordinarily classified in terms of chemistry based on nickel content in addition to the trace elements (iridium, gallium, and germanium) (Weisberg et al., 2006). Unfortunately, the required data of these traces were not completed; the nickel content and the nature of the kamacite lamellae were therefore relied upon. The iso-cooling curves from Goldsteina and Short (1967) indicate that Al-Sherqat meteorite which belongs to Group IIC has high cooling rates (Fig. 5). 


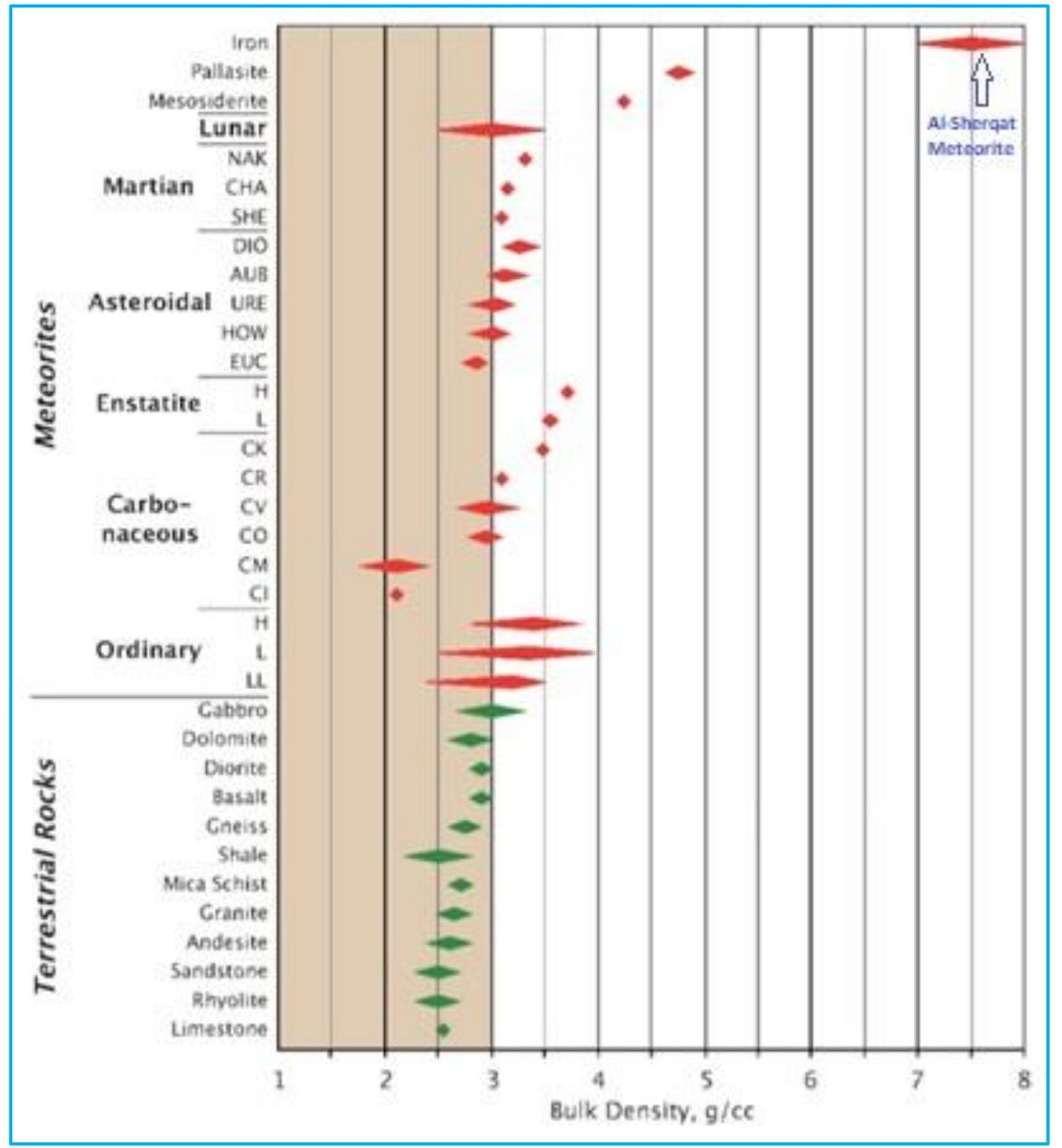

Fig. 4. Bulk densities of some terrestrial rocks and meteorites compared with Sherqat meteorite (Diagram after Norton and Chitwood, 2008)

Table 3. Classification of iron meteorite

\begin{tabular}{|c|c|c|c|c|}
\hline \multicolumn{5}{|c|}{ Bandwidth mm } \\
\hline Class & Abb. & $\begin{array}{c}\text { Brezina } \\
\text { (1885) }\end{array}$ & *Buchwald & Comments \\
\hline $\begin{array}{l}\text { Hexahedrite } \\
\text { Octahedrite }\end{array}$ & $\mathrm{H}$ & & $>50$ & Taenite absent \\
\hline Coarsest & Ogg & $>2.5$ & $>3.3$ & $\begin{array}{l}\text { Octahedral orientation of kamacite; } \\
\text { taenite usually present' }\end{array}$ \\
\hline Coarse & $\mathrm{Og}$ & $1.5-2.0$ & $1.3-3.3$ & $\begin{array}{l}\text { Og, Om, and Of display prominent } \\
\text { Widmanst [itten patterns }\end{array}$ \\
\hline Medium & Om & $0.5-1.0$ & $0.5-1.3$ & --- \\
\hline Fine & Of & $0.2-0.4$ & $0.2-0.5$ & --- \\
\hline Finest & Off & $<0.2$ & $<0.2$ & Continuous plate network \\
\hline Plessittic & Opl & & $<0.2$ & $\begin{array}{l}\text { Kamacite platelets do not form } \\
\text { continuous network }\end{array}$ \\
\hline Ataxite & $\mathrm{D}$ & --- & --- & $\begin{array}{l}\text { Fine plessite, generally some isolated } \\
\text { kamacite platelets }\end{array}$ \\
\hline Anomalous & Anom & --- & --- & Any other iron \\
\hline
\end{tabular}

*In Wasson (1970) 
Table 4. Structural and compositional properties of genetic group of iron meteorite (Mason, 1979)

\begin{tabular}{lccccc}
\hline Group & $\begin{array}{c}\text { Band width } \\
(\mathbf{m m})\end{array}$ & Structure & $\begin{array}{c}\mathbf{N i} \\
\mathbf{\%}\end{array}$ & $\begin{array}{c}\mathbf{G a} \\
\mathbf{p p m}\end{array}$ & $\begin{array}{c}\mathbf{G e} \\
\mathbf{p p m}\end{array}$ \\
\hline IA & $1.0-3.1$ & Om-Ogg & $6.4-8.7$ & $55-100$ & $190-520$ \\
IB & $0.01-1.0$ & D-Om & $8.7-25$ & $11-55$ & $25-19$ \\
IC & $<3$ & Onam-Og & $6.1-6.8$ & $49-55$ & $212-247$ \\
IIA & $>50$ & H & $5.3-5.7$ & $57-62$ & $170-185$ \\
IIB & $5-15$ & Ogg & $5.7-4.6$ & $64-59$ & $107-183$ \\
IIC & $\mathbf{0 . 0 6 - 0 . 0 7}$ & Opl & $\mathbf{9 . 3 - 1 1 . 5}$ & $\mathbf{3 7 - 3 9}$ & $\mathbf{8 8 - 1 1 4}$ \\
IID & $0.48-0.8$ & Of-Om & $9.6-11.3$ & $70-83$ & $82-98$ \\
IIE & $0.7-2.0$ & Anom & $7.5-9.7$ & $21-28$ & $62-75$ \\
IIIA & $0.9-1.3$ & Om & $7.1-9.3$ & $17-23$ & $32-47$ \\
IIIB & $0.6-1.3$ & Om & $8.4-10.5$ & $16-21$ & $27-46$ \\
IIIC & $0.2-0.4$ & Off-Of & $10-13$ & $11-27$ & $8-70$ \\
IIID & $0.01-0.05$ & D-Off & $16-23$ & $1.5-5.2$ & $1.4-4.0$ \\
IIIE & $1.3-1.6$ & Og & $8.2-9.0$ & $17-19$ & $34-37$ \\
IIIF & $0.5-1.5$ & Om-Ogt & $6.8-7.8$ & $6.3-7.2$ & $0.7-1.1$ \\
IVA & $0.25-0.45$ & Of & $7.4-9.4$ & $1.6-2.4$ & $0.09-0.14$ \\
IVB & $0.006-0.03$ & D & $16-26$ & $0.17-0.27$ & $0.03-0.07$ \\
\hline
\end{tabular}

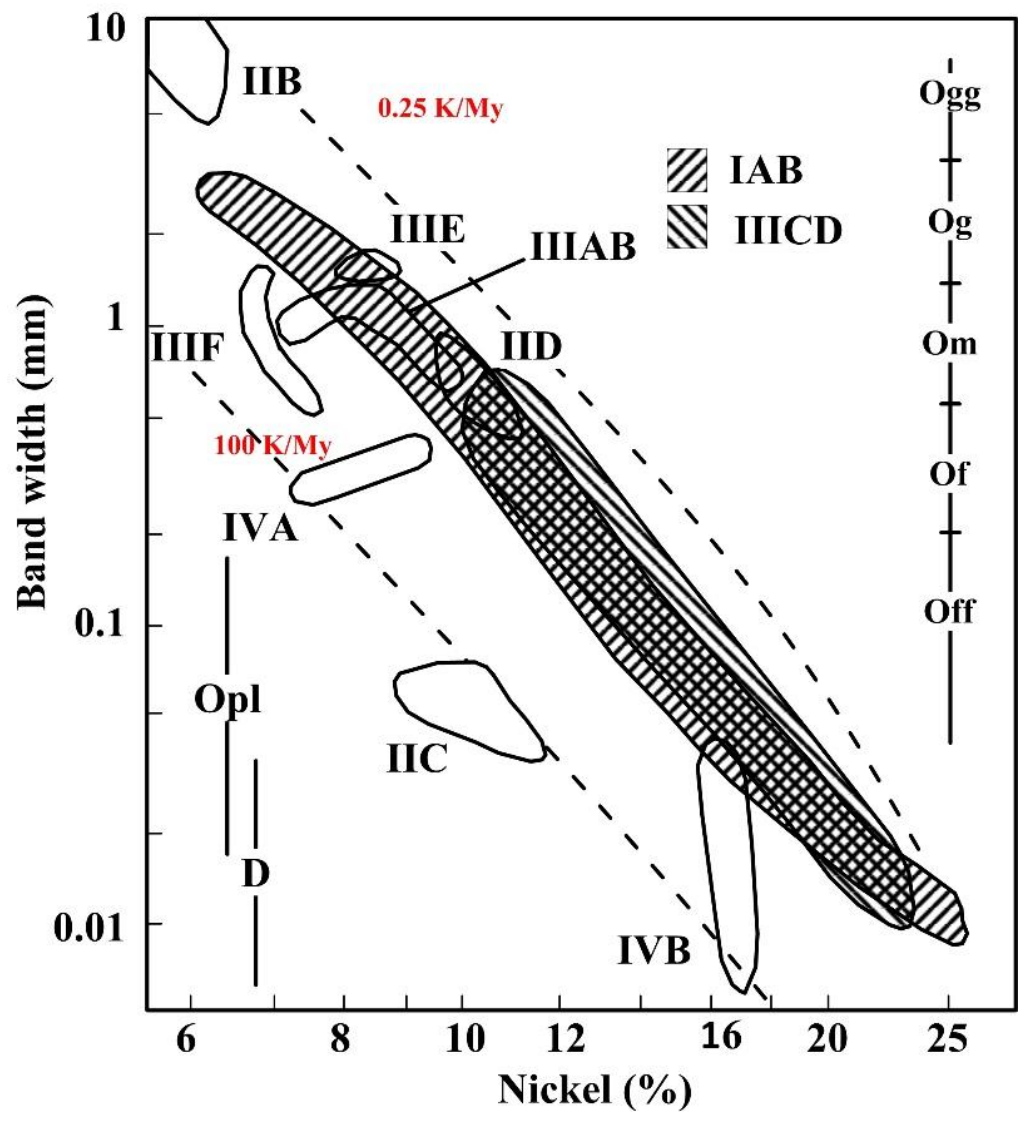

Fig. 5. Logarithmic plot of kamacite bandwidth against bulk Ni content showing the outline of the groups. Diagonal lines are isocooling curves from Goldsteina and Short (1967). Groups IIC, IVA, and

IVB have high cooling rates resulting in characteristic structures which may be easily recognized.

Groups 1AB, IID, IIIB, and IIICD have cooled more slowly and lie within the error limits of a $2 \mathrm{~K}$ My

${ }^{1}$ cooling curve. Also shows the bandwidth ranges for the various structural classes. Diagram after Scott and Wasson, 1975. 


\section{Discussion}

The iron meteorites are mainly composed of an iron-nickel alloy with small amounts of sulfide and carbide minerals exhibiting Widmanstätten patterns which reflect varying levels of nickel bands interleaving with taenite (Sephton, 2002; Elkins-Tanton et al., 2020). Most of them are cores of asteroids that melted early in their history. Genetically, they are most belong to monogenic, and few are polygenic (Farrington, 1901). It is typical to consider that kamacite is contained 90-95\% Fe and 5-10\% Ni forming $\mathrm{Fe} 0.9 \mathrm{Ni0} .1$ with trace elements. Kamacite is either hexahedrite or octahedrite. Hexahedrites meteorite is containing less than $6 \% \mathrm{Ni}$ having a hexahedral pattern of large single-crystal (centimeter-thick) kamacite. Octahedrite are those containing 6-16\% Ni crystallize in an octahedral pattern with very thin $(<0.2 \mathrm{~mm}$ ) kamacite lamellae (Zolensky et al., 2018). Iron meteorites containing less than $16 \% \mathrm{Ni}$ are named Ni-rich ataxites formed at low temperature and lacking in Widmanstätten pattern, and they could not form over the 4.55 billion years of solar system history (Zolensky et al., 2018). The Ni-poor ataxites are hexahydrate or octahedrite reheated in massive impacts after they fell on Earth. Iron meteorites have relatively low $\mathrm{Ni}$ contents, for instance, hexahydrate and coarse octahedrite are formed at pressures slightly higher than those of higher Ni contents which are fine octahedrite and nickel-rich ataxites (Lovering and Parry,1962). The shock-induced deformations are common microstructural features in iron meteorites (Wasson, 1970; Buchwald, 1975 and Olsen et al., 1994). Widmanstätten patterns form during decreasing the temperature of meteorite, where iron and nickel coexist at high temperatures. The meteorite is initially formed at temperatures above $1500{ }^{\circ} \mathrm{C}$ in the form of completely molten taenite, and when it cools below $723{ }^{\circ} \mathrm{C}$, the initial phase changes; so that the kamacite begins to accelerate. Widmanstätten patterns are formed and can be greatly affected by the temperature, pressure, and composition of the meteorite (Goldstein 1965). Meteorites are linked to M-type, C-type, and D-type. Iron meteorites belonging to M-type are considered metallic core fragmented by impact asteroids. Ctype is represented the carbonaceous asteroids having a large quantity of carbon. They occur most frequently at the outer edge of the asteroid belt, 3.5 astronomical units from the Sun, (Fitzsimmons et al., 1994; Asphaug, 2016). D-type asteroids are composed of organic-rich silicates, carbon, and anhydrous silicates, possibly with water ice They are found in the outer asteroid belt and beyond. The current chemical classification scheme depends mainly on the relationship between the quantities of $\mathrm{Ga}$, $\mathrm{Ge}$, and $\mathrm{Ir}$ as trace elements relating to their proportions in the asteroid parent bodies (Norton, 2002). Weisberg et al. (2006) have classified iron meteorites chemically into 13 groups (IAB, IC, IIAB, IIC, IID, IIE, IIIAB, IIICD, IIIE, IIIF, IVA, IVB, and IIG). The IIC type is a chemical classification that requires knowledge of the nitrates of iridium, gallium, and germanium. The IIC group is characterized by octahedrite, $9.3-11.5 \% \mathrm{Ni}, 37-39 \mathrm{ppm} \mathrm{Ga}, 88-114 \mathrm{ppm} \mathrm{Ge}, 4-11$ ppm Ir, Ge-Ni correlation positive (Scott and Wasson, 1975). Unfortunately, Al-Sherqat meteorite was not analyzed for Ir, Ga, and Ge, and was classified as an iron meteorite, IIC, plessitic (Opl) octahedrite group based on the amount of nickel (9.63\%) and the nature of the octahedrite kamacite sheets which exhibits not continuous network platelets with a bandwidth of less than $0.2 \mathrm{~mm}$. The structural classification included hexahydrate and octahedrite is depending on the structural relationship between iron and nickel that form or not form the Widmanstätten patterns. Hexahedrites $(\mathrm{H})$ is less common and characterized by low $\mathrm{Ni}$ and no Widmanstätten patterns; whereas octahedrite $(\mathrm{O})$ are most common having Widmanstätten patterns that distinct by average to high $\mathrm{Ni}$ and subdivided into Ogg, Og, Om, Of, Off, Opl based on the width of the kamacite lamellae (Henderson, 1965). The lamellae width in the structural classes can be described from coarsest to finest as coarsest $\mathrm{Ogg}>3.3 \mathrm{~mm}$, Coarse $(\mathrm{Og}) 1.3-3.3 \mathrm{~mm}$, Medium $(\mathrm{Om})$ $0.5-1.3 \mathrm{~mm}$, Fine (Of) $0.2-0.5 \mathrm{~mm}$, Finest (Off) $<0.2 \mathrm{~mm}$, Plessitic (Opl) a transitional structure between octahedrite and ataxites (D) which contains very high nickel. The IIC type of iron meteorite is often contained daubréelite $\left(\mathrm{FeCr}_{2} \mathrm{~S}_{4}\right)$, schreibersite $(\mathrm{Fe}, \mathrm{Ni})_{3} \mathrm{P}$. The Al-Sherqat meteorite is composed of kamcite, taenite, schreibersite, daubréelite, pentlandite, chromite, and wusite. 


\section{Conclusions}

The Al-Sheraqt meteorite is considered the first visible iron meteorite that fell in Iraq. It has consisted mainly of iron-nickel alloy that is composed of iron (86.9 wt\%) and nickel (9.63 wt \%) with the proportion of $\mathrm{Fe} / \mathrm{Ni}$ 9.02. It was classified structurally as octahedral (Opl group), and chemically as an M-type IIC group as the majority of Fe exhibited an octahedral array of kamacite $(\gamma-\mathrm{Fe}, \mathrm{Ni})$ bands with less than $0.2 \mathrm{~mm}$ wide. Kamacite, taenite, schreibersite, daubréelites, pentlandite, chromite, and wusite are the bulk mineralogical composition of Al-Sherqat meteorite forming a distinctive crystalline structure of Widmanstätten patterns. The liquid phase of iron and nickel was cooled over millions of years, resulting in the formation of the Widmanstätten Pattern. It is believed a core of asteroids coming from the belt of asteroids in the solar system. The crystallinity of meteorite indicates a short time fusion with moderate time cooling.

\section{Acknowledgements}

The authors are very grateful to Mr. Ahmad Mohamad Atiya who saw the meteorite falling, collected it, told us the event, and then provided us with a small piece of it that is currently investigated. The authors are very grateful to the Secretary of Journal Mr. Samir R. Hijab, the Technical Editors, and the reviewers for their great efforts and valuable comments.

\section{References}

Asphaug, E., 2016. Rise and fall of the Martian moons. Nature Geoscience, 9(8), 568-569.

Brezina, A., 1885. Die Meteoritensammlung des K. k. mineralogischen Hofkabinetes in Wien am 1. mai 1885. A. Hölder, K. k. hof-und Universitäts-Buchhändler.

Buchwald, V.F., 1975. Handbook of Iron Meteorites. Their History, Distribution, Composition and Structure. Arizona: State University.

Craig, J.R., Vaughan, D.J. and Hagni, R.D., 1981. Ore microscopy and ore petrography, New York: Wiley.

Dell'Aglio, M., De Giacomo, A., Gaudiuso, R., De Pascale, O., Senesi, G.S. and Longo, S., 2010. Laser induced breakdown spectroscopy applications to meteorites: chemical analysis and composition profiles. Geochimica et Cosmochimica Acta, 74(24), 7329-7339.

Elkins-Tanton, L.T., Asphaug, E., Bell III, J.F., Bercovici, H., Bills, B., Binzel, R., Bottke, W.F., Dibb, S., Lawrence, D.J., Marchi, S. and McCoy, T.J., 2020. Observations, meteorites, and models: a preflight assessment of the composition and formation of (16) Psyche. Journal of Geophysical Research: Planets, 125(3), 2019JE006296.

Farrington, O.C., 1901. The Structure of meteorites. The Journal of Geology, 9(1), 51-66.

Fitzsimmons, A., Dahlgren, M., Lagerkvist, C.I., Magnusson, P. and Williams, I.P., 1994. A spectroscopic survey of D-type asteroids. Astronomy and Astrophysics, 282, 634-642.

Goldstein, J. I., and J. M. Short, 1967. The iron meteorites, their thermal history and parent bodies, Geochim. Cosmochim. Acta, 31, 1733-1770.

Goldstein, J.I., 1965. The formation of the kamacite phase in metallic meteorites. Journal of Geophysical Research, 70(24), 6223-6232.

Granvik, M. and Brown, P., 2018. Identification of meteorite source regions in the solar system. Icarus, 311, 271287.

Henderson, E.P., 1965. Hexahedrites. Smithsonian Miscellaneous Collections.

Howe, J.B. and Knott, E.F., 1962. A Study of the Physical and Electrical Properties of Chrondrite Meteorites. University of Michigan. Radiation Laboratory.

Khalaf, S.Z., Yassin, A.T., Awadh, S.M. and Jassim, R.Z., 2015. Mineralogy texture and chemistry of the Ellicott meteorite using scanning electron microscope and energy disperse spectroscopy (SEM/EDS). Arabian Journal of Geosciences, 8(7), 4819-4831. 
Litasov, K.D., Teplyakova, S.N., Shatskiy, A. and Kuper, K.E., 2019. Fe-Ni-PS melt pockets in Elga IIE iron meteorite: Evidence for the origin at high-pressures up to $20 \mathrm{GPa}$. Minerals, 9(10), p.616.spectroscopic survey of D-type asteroids. Astronomy and Astrophysics, 282, 634-642.

Lovering, J.F. and Parry, L.G., 1962. Thermomagnetic analysis of co-existing nickel-iron metal phases in iron meteorites and the thermal histories of the meteorites. Geochimica et Cosmochimica Acta, 26(3), 361-382.

Mason, B.H., 1979. Cosmochemistry: Meteorites. US Department of the Interior, Geological Survey.

Norton, O.R. and Chitwood, L.A., 2008. Primitive and Differentiated Meteorites: Asteroidal Achondrites. In: Field guide to meteors and meteorites. Patrick Moore's Practical Astronomy Series. Springer, London.

Norton, O.R., 2002. The Cambridge encyclopedia of meteorites, 374.

Novotny, P.M., Goldstein, J.I. and Williams, D.B., 1982. Analytical electron microscope study of eight ataxites. Geochimica et Cosmochimica Acta, 46(12), 2461-2469.

Olsen, E., Davis, A., Clarke Jr, R.S., Schultz, L., Weber, H.W., Clayton, R., Mayeda, T., Jarosewich, E., Sylvester, P., Grossman, L. and Wang, M.S., 1994. A new link in the HE iron chain. Meteoritics, 29(2), 200-213.

Scott, E.R. and Wasson, J.T., 1975. Classification and properties of iron meteorites. Reviews of Geophysics, 13(4), 527-546.

Sephton, M.A., 2002. Organic compounds in carbonaceous meteorites. Natural product reports, 19(3), 292-311.

Wasson, J.T., 1969. The chemical classification of iron meteorites-III. Hexahedrites and other irons with germanium concentrations between 80 and 200 ppm. Geochimica et Cosmochimica Acta, 33(7), 859-876.

Wasson, J.T., 1970. The chemical classification of iron meteorites: IV. Irons with Ge concentrations greater than $190 \mathrm{ppm}$ and other meteorites associated with group I. Icarus, 12(3), 407-423.

Weisberg, M.K., McCoy, T.J. and Krot, A.N., 2006. Systematics and evaluation of meteorite classification. Meteorites and the early solar system II, 19.

Yang, J. and Goldstein, J.I., 2004, March. Nucleation of the Widmanstatten Pattern in Iron Meteorites. In Lunar and Planetary Science Conference, 1288.

Yang, J., Goldstein, J.I., Scott, E.R.D., Michael, J.R., Kotula, P.G., Pham, T. and McCOY, T.J., 2011. Thermal and impact histories of reheated group IVA, IVB, and ungrouped iron meteorites and their parent asteroids. Meteoritics \& Planetary Science, 46(9), 1227-1252.

Zolensky, M.E., Abreu, N.M., Velbel, M.A., Rubin, A., Chaumard, N., Noguchi, T. and Michikami, T., 2018. Physical, chemical, and petrological characteristics of chondritic materials and their relationships to small solar system bodies. In Primitive Meteorites and Asteroids, 59-204. 